\title{
Indicadores da Qualidade na Educação: as agendas das escolas orientando a política educacional de municípios
}

*Professora da Faculdade de Educação da Unicamp

E-mail: bethbarolli@gmail.com

**Assessora na Ação Educativa

E-mail: claudia.bandeira@ acaoeducativa.org
Resumo: Este artigo analisa uma metodologia de autoavaliação institucional para escolas: os Indicadores da Qualidade na Educação e suas contribuições em processos participativos de construção de planos educacionais, cujo uso tem sido recomendado pela Ação Educativa em parceria com a Undime e o MEC. O principal objetivo dos Indicadores é a participação da comunidade escolar na luta pela melhoria da qualidade na educação. A análise será feita considerando desafios para o campo da educação: participação em processos educacionais; avaliação da escola e legitimidade frente aos responsáveis pelas decisões. Conclui-se, a partir de uma experiência, que o material mencionado é potencialmente efetivo na sua capacidade de ampliar o diálogo entre a escola e os órgãos dos sistemas educacionais e que legitima e dá força para exigir das instâncias centrais as condições requeridas para uma educação de melhor qualidade.

Palavras-chave: Autoavaliação da escola. Participação educacional. Processos avaliativos educacionais. Qualidade na educação. Planos educacionais. 
A criação de diversos colegiados no âmbito educacional foi incentivada no Brasil, sobretudo a partir da década de 1980, na perspectiva de implementar um processo de gestão democrática capaz de envolver a comunidade como um todo na definição de metas e estratégias a favor da melhoria da qualidade da educação. A LDB, em sua versão de 1996, propõe a gestão democrática como princípio da educação nacional efetivado pela participação de todos na concepção e condução de novos processos de gestão e de organização do espaço escolar. É nessa direção que foram criadas em grande parte das escolas públicas do país instâncias como o conselho fiscal do Fundeb, o conselho da merenda escolar, conselhos com funções normativas, como os de educação em nível estadual e municipal grêmios estudantis conselhos de classe e os escolares ou as associações de pais e mestres (BRITO; BORGES, 2012). Boa parte dessas instâncias tem como pressuposto a importância e a urgência de se empreender por parte das escolas um processo participativo que contribua para a construção de uma sociedade mais justa e democrática. A avaliação institucional com a participação da comunidade escolar coloca-se, então, como uma perspectiva promissora para a proposição de planos educacionais que envolvem a elaboração do regimento acadêmico, projeto político-pedagógico, calendário escolar, orientações curriculares, metodológicas, didáticas e administrativas.

Há que se considerar, ainda, que a avaliação institucional faz-se necessária para que se possa avaliar de forma contextualizada o desempenho dos estudantes. Ou seja, a escola precisa ser avaliada em sua totalidade, “integrando a avaliação do desempenho do aluno, não sendo possível pensar-se em modificar a sistemática de avaliação vigente sem encarar uma transformação global da escola" (SOUSA, 2006).

Um processo participativo, no entanto, não se constrói apenas com a legislação. A realidade tem oferecido vários indícios de que esse processo requer aprendizagem contínua e, ainda, que precisa ser sustentado para poder se constituir numa prática social orientada pela busca de uma intervenção constante na definição de políticas públicas.

No município de Bebedouro/SP, o Departamento Municipal de Educação - Demec - mostrou clareza em relação a essa perspectiva na medida em que reconheceu a necessária participação da comunidade escolar para que pudesse elaborar um plano capaz de abranger a rede como um todo e, ao mesmo tempo, atender demandas específicas de cada escola. Para levar 
adiante sua intenção de construir de forma democrática um plano de gestão educacional, o Demec abraçou a metodologia dos Indicadores da Qualidade na Educação ${ }^{1}$ - o Indique -, concebido pela Ação Educativa em 2003 com apoio do Pnud e incentivo financeiro do Unicef, em que foi elaborado um sistema de indicadores populares de qualidade da escola.

o Departamento, por sua vez, sente que vai ter que fazer aquilo que nós chamamos de Plano Municipal de Educação [...] nós tivemos aqui um Congresso Estadual dos Conselhos Municipais de Educação [...] em 2003. Tivemos muitos professores que vieram de outros estados, inclusive, fazer as palestras para que a gente pudesse construir o nosso Plano Municipal de Educação. Foi construído através dos Conselhos, através das comissões, só que ficou no papel. Acabou não indo para a câmara para ser aprovado. Posteriormente, esse Plano Municipal de Educação foi construído por um escritório e o que acabou acontecendo? Foi feito, foi aprovado, mas realmente não tinham alguns anseios da comunidade escolar [...]. Então o que acontece? Quando eu voltei para o Departamento, a gente sentiu necessidade de organizar alguns conselhos regionais para tentar democratizar mais as ações do Departamento. E eu vejo que vai ser muito importante [o Indique], inclusive para a gente construir o nosso Conselho Municipal 2 de Educação e o Planejamento do Departamento de Educação (dirigente do Demec, 7 abr. 2011)

O Projeto Indicadores da Qualidade na Educação - Indique - foi desenvolvido com o objetivo de construir e disseminar um conjunto de indicadores educacionais qualitativos, com fácil compreensão, que fosse capaz de envolver os diferentes atores da comunidade escolar - alunos, professores, gestores, familiares, funcionários, representantes de organizações locais, etc. - em torno de uma avaliação participativa. Na perspectiva de criar condições efetivas para a democratização da escola, o projeto foi concebido para que a comunidade reunida possa avaliar sua realidade, identificar prioridades, estabelecer planos de ação, implementar e monitorar seus resultados.

O Projeto subsidiou atividades de formação com gestores e equipes escolares de redes de ensino municipais e estaduais, mostrando-se potencialmente efetivo na sua capacidade de engajar as comunidades escolares em processos participativos voltados para a melhoria da qualidade na educação pública.

Atualmente existem três versões dos Indicadores da Qualidade na Educação: a do Ensino Fundamental (2004, 2006, 2007 e 2013), a da Educação Infantil (2009) e os Indicadores Relações Raciais na Escola (2013). A partir de 2013 iniciou-se um processo de estímulo do uso desses Indicadores na construção participativa de Planos Estaduais e Municipais de Educação, uma iniciativa de Ação Educativa, Unicef, Undime, Uncme, Campanha Nacional pelo Direito à Educação, Anpae e Instituto C\&A (www.deolhonosplanos.org.br). No município de Bebedouro, a rede de ensino utilizou os Indicadores da Qualidade na Educação - Ensino Fundamental e Educação Infantil, porém, este artigo faz análise do universo de escolas que utilizaram os - Ensino Fundamental.

Os depoimentos compartilhados no texto foram concedidos para a equipe de assessores da Ação Educativa (Claudia Bandeira, Paulo Neves e Luís Serrão) com o objetivo de registrar o processo de utilização dos Indicadores da Qualidade na Educação no município de Bebedouro. 
Neste depoimento da dirigente do Demec fica evidente o fato de que a proposição de indicadores externos que se pautam, sobretudo, em informações que configuram a situação educacional em nível macro podem não refletir aquilo que a comunidade escolar mais precisa para caminhar em direção a uma educação de qualidade. Sem dúvida, a variedade de temáticas ou de agendas que perpassam as realidades escolares não pode ser facilmente abarcada por pesquisadores e tecnocratas que, via de regra, não observam e não interrogam a realidade escolar da mesma perspectiva que as pessoas que a vivem no cotidiano (RIBEIRO; RIBEIRO; GUSMÃO, 2005, p. 231). 0 próprio conceito de qualidade tem se mostrado bastante complexo e só ganha legitimidade quando fomentado pelo debate coletivo e participativo, aberto a toda a comunidade. Como observa Corrêa (2003), o termo 'qualidade' não pode ser traduzido num único conceito, universal e absoluto, já que diferentes setores da sociedade e diferentes políticas educacionais podem tomá-lo de modo absolutamente diverso.

A proposta do Indique ao reconhecer em sua concepção a relevância de fazer valer a voz da comunidade escolar busca a mobilização e o comprometimento de todos os envolvidos com a definição de metas que vão ao encontro do que compreendem por uma educação de qualidade. É nessa mesma direção que Aguerrondo (1993, p. 570) afirma que “a qualidade da educação é específica a cada conjuntura, implicando e dependendo da capacidade de integração das dimensões político-ideológica e técnico-pedagógica”.

Cabral e Di Giorgi (2011) consideram que a proposta do Indique apoia-se num modelo de prática educacional que estimula a participação de alunos e da comunidade escolar como um todo nas fases do processo educacional, visando à melhoria da qualidade do ensino, muito em acordo ao que propõe Paulo Freire.

Precisamos contribuir para criar a escola que é aventura, que marcha, que não tem medo do risco, por isso que recusa o imobilismo. A escola em que se pensa, em que se cria, em que se fala, em que se adivinha, a escola que apaixonadamente diz sim à vida (FREIRE, 1995, p. 57).

Porém, criar essa escola almejada por Paulo Freire requer a implantação de um processo no qual a escola seja problematizada pela própria comunidade em que está inserida. Parece que somente quando a comunidade escolar está implicada com sua autoavaliação, sem medo de enfrentar suas dificuldades e de buscar soluções para seus problemas, ela poderá planejar e executar ações que visem a uma educação de qualidade. 
A proposta dos Indicadores da Qualidade na Educação elegeu a pesquisa-ação como metodologia de investigação na qual a comunidade escolar configurase como a responsável pela produção de conhecimento sobre ela mesma e, ao mesmo tempo, o sujeito dessa produção. Desse modo, como considera Gamboa (1982, p. 36), a pesquisa-ação “busca superar, essencialmente, a separação entre conhecimento e ação, buscando realizar a prática de conhecer para atuar".

No âmbito da proposta do Indique essa metodologia é marcada por algumas etapas significativas: preparação e estudo do material; mobilização da comunidade escolar; avaliação participativa; elaboração e implementação dos planos. No caso de Bebedouro, as técnicas do Demec acompanharam todo esse processo com a assessoria da equipe da Ação Educativa. Houve um acompanhamento sistemático que não só procurou sustentar a participação da comunidade escolar nas diferentes etapas, manter uma escuta sobre os desafios postos pelas escolas, apoiar a definição e a avaliação das estratégias constituintes dos planos, como também procurou, a partir das agendas das escolas, subsidiar a elaboração dos projetos político-pedagógicos - PPPs - das unidades escolares e, consequentemente, a Política Educacional do Município.

Porque [...] a gente pensava em fazer por meio de uma gestão democrática [...] e sentimos que é uma ferramenta que dá para atingir este objetivo [...) com o Indique teremos subsídios para, futuramente, elaborar o PPP da escola, o planejamento do Departamento, o plano de trabalho do Departamento (dirigente do Demec, 7 abr. 2011).

Os Indicadores da Qualidade na Educação traduzem sua concepção de qualidade em sete dimensões:

- Ambiente educativo - busca auxiliar a escola num estudo sobre os modos pelos quais as regras de convivência e de cidadania são geridas pela própria comunidade escolar.

- Prática pedagógica e avaliação - focaliza o compromisso da comunidade escolar com a elaboração e execução de seu projeto político-pedagógico, sobretudo no que se refere ao planejamento do ensino, ao desenvolvimento de uma prática pedagógica inclusiva, às formas de avaliação dos alunos e ao acompanhamento dos processos de ensino e de aprendizagem.

- Ensino e aprendizagem da leitura e da escrita - busca diagnosticar a situação da escola no que se refere à implementação e ao acompanhamento de práticas educativas que tenham como meta o aprendizado da leitura e da escrita pelos alunos. 
- Gestão escolar democrática - avalia a existência e o uso de espaços democráticos nas escolas e a socialização das informações e decisões acordadas nesses espaços.

- Formação e condições de trabalho dos profissionais da escola - permite entender a situação da escola no que se refere à formação inicial e continuada de seus profissionais, bem como a estabilidade do corpo docente, a relação entre o número de professores e o de alunos e a assiduidade da equipe escolar.

- Ascondiçõesarquitetônicasquecompõemoambientedaescolatambém são consideradas para avaliação no âmbito da dimensão ambiente físico escolar. São avaliados não apenas os recursos, equipamentos e materiais pedagógicos, como também a funcionalidade e as condições que podem contribuir para compor um ambiente confortável e propício para o trabalho pedagógico.

- Por fim, a dimensão acesso e permanência dos alunos na escola busca contribuir para que as escolas focalizem atenção especial nos alunos que faltam e nos que têm defasagem de aprendizagem; pretende, ainda, oferecer elementos para que a questão do abandono e da evasão seja considerada de forma responsável pela comunidade escolar.

Em síntese, a concepção do Indique está sustentada em quatro princípios considerados por Sousa (2006, p. 139) como fundamentais para empreender um processo de avaliação escolar efetivo que contribua para a melhoria da qualidade educativa:

- Ser democrático, ao considerar que a comunidade escolar é capaz de implicar-se com os interesses da maioria da população.

- Ser abrangente, ao se dispor a avaliar todos os componentes da organização escolar.

- Ser participativo, ao prever que todos poderão colaborar com todo o processo avaliativo, desde a mobilização da comunidade até o monitoramento das ações e dos seus resultados.

- Ser contínuo, ao pretender uma prática dinâmica de investigação.

\section{Percursos dos Indicadores da Qualidade na Educação em Bebedouro}

A parceria entre o Departamento Municipal de Educação de Bebedouro e a Ação Educativa para conduzir e sustentar o processo de avaliação participativa da rede de ensino foi prevista para acontecer durante dois anos, sendo que as técnicas do Demec se responsabilizaram pelo acompanhamento das avaliações e da execução dos planos de ação nas escolas. A assessoria da 
Ação Educativa esteve mais voltada para a reflexão sobre as ações realizadas pelas equipes escolares e do Demec, por meio de encontros regulares de formação que precediam os encontros de acompanhamento do Demec a todas as escolas.

Para a utilização dos Indicadores da Qualidade na Educação pela rede de ensino de Bebedouro, foram realizadas reuniões entre as técnicas do Demec e as diretoras das unidades escolares, onde foram discutidas as contribuições que o uso do material poderia trazer tanto para o Departamento, como para as escolas.

Olha, ela [avaliação Indique] veio ao encontro das nossas expectativas, porque toda época de elaboração do PPP a gente fica com aquela dificuldade mesmo, porque nós realizávamos uma avaliação institucional, mas [...] sem ter um parâmetro [...] isso só facilitou o trabalho da gente na escola (diretora de escola, 6 abr. 11).

De acordo com o depoimento da diretora, nota-se que a avaliação realizada por meio do Indique subsidiou a elaboração ou revisão do projeto políticopedagógico da escola. Na perspectiva de Sousa (1995, p. 63), a avaliação institucional

compreende a descrição, interpretação e o julgamento das ações desenvolvidas, resultando na definição de prioridades a serem implementadas e rumos a serem seguidos, tendo como referência princípios e finalidades estabelecidas no Projeto da Escola, ao mesmo tempo em que subsidia a sua própria redefinição.

Certamente, a redefinição dos PPPs das escolas de forma participativa subsidia também o Departamento de Educação para implementar sua política educacional. Assim, a utilização dos Indicadores da Qualidade na Educação em Bebedouro possibilitou um estudo das demandas específicas de cada unidade educacional e das principais agendas da rede de ensino como um todo. As experiências de uso dos Indicadores em outros municípios do Brasil evidenciaram que

Quando utilizado em toda a rede de ensino, o Indique pode levar à troca de conhecimentos entre as escolas; tornar mais próxima e confiável a relação entre as Secretarias e instituições; fortalecer a responsabilidade pela educação por escolas e Secretarias, clareando os papéis de cada um (RIBEIRO; GUSMÃO, 2010, p. 846).

A gente achou que seria legal ter um retrato de toda a rede municipal, desde a educação infantil até o fundamental [...] saber como está a nossa escola aqui em Bebedouro até para poder fazer um trabalho de gestão mais adequado ao que seria a necessidade das nossas escolas aqui no município (técnica do Demec, 6 abr. 2011) 
Para a realização das avaliações nas escolas, a equipe do Demec contribuiu com a etapa de mobilização das comunidades escolares, por meio do incentivo à participação dos conselheiros escolares e de outras instituições relacionadas com a educação e com a defesa dos direitos de crianças e adolescentes. Investiu também em uma ampla divulgação nos meios de comunicação locais, tudo isso acordado com as gestoras das escolas em reuniões de planejamento da avaliação.

Fizemos reunião com os gestores, confeccionamos banners e faixas para cada unidade escolar, folhetos e convites para todos os alunos, todos padronizados para toda a rede, e outdoors distribuídos pela cidade, utilizando padrão do próprio Indique. A C. [dirigente de ensino] deu entrevistas a respeito do que seria o Indique, solicitando que a população fosse até a escola de seu bairro, que a família fosse até a escola de seu filho e contribuísse com sua opinião. Estas entrevistas saíram nos jornais, rádio da cidade e site da prefeitura. [...] Foi decidido também que cada escola faria seu próprio material de divulgação, faria um trabalho com a equipe interna para mobilização, enfeites para recepcionar a comunidade. Montamos um cronograma com os gestores [...] para que muitas escolas não escolhessem o mesmo dia, pois todas as pessoas do Demec fariam o acompanhamento e participariam (técnica do Demec, 31 out. 2011).
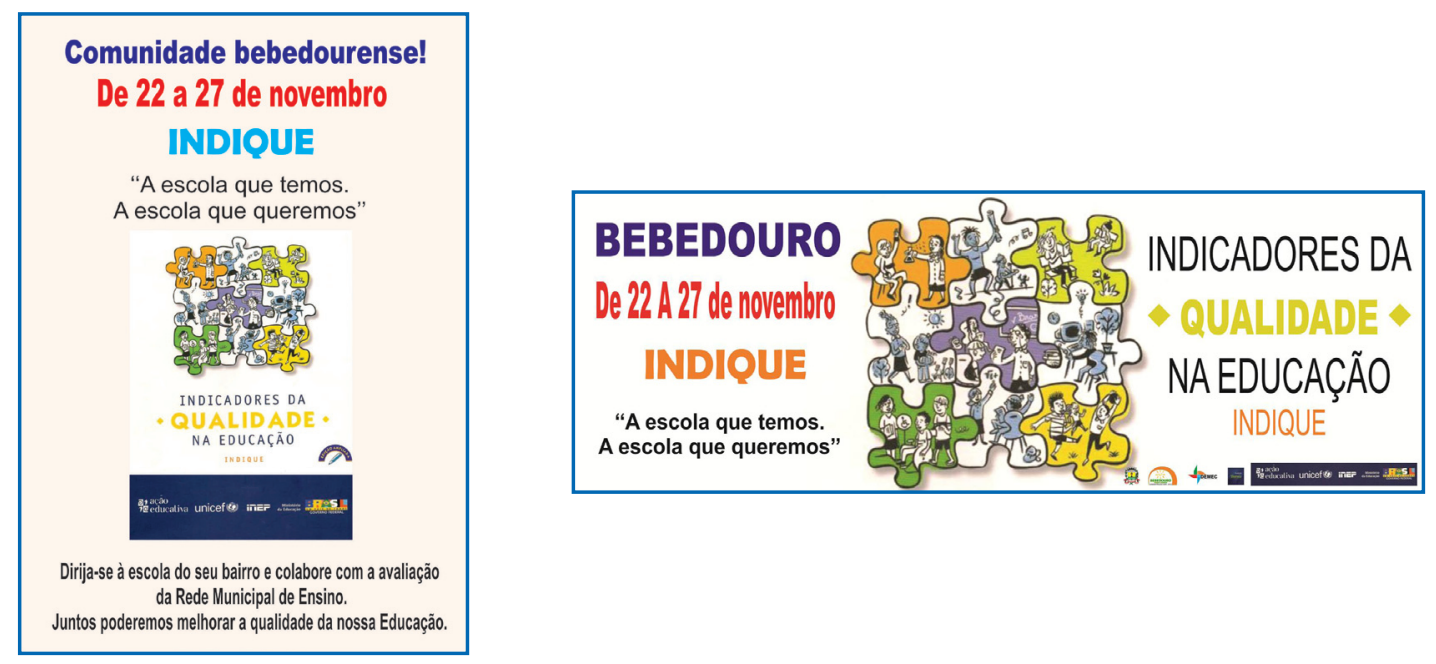

Banners produzidos pelo Departamento de Educação para mobilizar a comunidade.

O que se percebe é um esforço da equipe do Demec na construção de um sentido da avaliação junto à comunidade escolar, que se inicia com a mobilização da comunidade. Porém, não apenas o Departamento investiu na divulgação do processo avaliativo; as escolas também se envolveram, criando estratégias para divulgar e preparar a comunidade. 
Com os professores nós fizemos em duas etapas, a gente estudou todas as dimensões e orientou. Com os alunos nós fizemos uma reunião mais rápida explicando o que era o Indique, o que ia acontecer e [...] eles compareceram. E com os familiares a gente fez uma prévia em uma reunião de pais [...] então a gente colocou o que ia acontecer, como era e por que precisávamos deles na escola (diretora de escola, 6 abr. 2011).

A mobilização da comunidade escolar para a avaliação é o momento da conquista para a participação. Quanto mais pessoas participarem da avaliação da escola e se engajarem em ações para sua melhoria, mais democrático poderá ser o processo e maiores poderão ser os ganhos para a educação. $\mathrm{Na}$ visão de Fernandes,

a participação na avaliação de, pelo menos, os principais intervenientes num dado projecto, garante a diversidade de pontos de vista sobre o seu mérito e o seu valor, permitindo uma visão mais rigorosa das realidades que se pretendem avaliar (2009, p. 6).

Tabela 1 - Presença nas autoavaliações das escolas de ensino fundamental de Bebedouro (SP)

\begin{tabular}{|l|c|c|}
\hline Segmentos & № & $\%$ \\
\hline Familiar/responsável & 511 & $40,1 \%$ \\
Docentes & 270 & $21,2 \%$ \\
Estudantes & 247 & $19,4 \%$ \\
Funcionários & 139 & $10,9 \%$ \\
Coordenadores pedagógicos & 26 & $2 \%$ \\
Diretores & 23 & $1,8 \%$ \\
Profissional do Demec & 23 & $1,8 \%$ \\
Comunidade ampliada/ & 23 & $1,8 \%$ \\
Profissionais de instituições parceiras & 16 & $1,2 \%$ \\
Não identificados & 1.275 & $100 \%$ \\
Total & &
\end{tabular}

Fonte: Listas de presença dos participantes das avaliações realizadas nas escolas (dezembro 2010).

No caso de Bebedouro foram 1.275 membros das comunidades escolares que participaram das avaliações do Indique nas 12 escolas de ensino fundamental da rede ${ }^{3}$, uma média de aproximadamente cem pessoas em cada unidade educacional. Cabe destacar que cerca de $42 \%$ dos participantes das avaliações não atuam diretamente no cotidiano da escola, mas se envolveram nas discussões sobre sua melhoria.

Essa mobilização foi bastante expressiva e colaborou de forma decisiva para que o processo de avaliação das escolas a partir das dimensões e dos indicadores propostos pelo Indique tenha sido realizado com muito envolvimento dos participantes. Os resultados da avaliação das escolas foram sistematizados pela equipe da Ação Educativa e devolvidos ao Demec que, posteriormente, convocou representantes de cada escola para formalizar uma primeira versão do plano de ação e encaminhar sua implementação.

3 Como a Escola Municipal de Educação Básica Izabel Motta foi dividida em duas unidades situadas em diferentes distritos, foi contabilizada no estudo como duas escolas. 
Nós marcamos um horário individualmente para cada escola, uma hora, onde a gente sentou junto, eu e a E. Sentamos juntas, tentamos dar uma olhada no que foi devolvido, o que foi tabulado. [...] E assim, foi um momento de ouvir o que eles já tinham percebido e o que eles já estavam fazendo, também. Então achei bom a gente ter feito dessa forma, cada um com o ${ }^{4}$ seu espaço, para a gente tentar ver aquela escola individualmente. [...] Mas a gente chamou atenção para aqueles verdes que tinham comentários, que na verdade eram amarelos. Teve uma gestora da educação infantil, que foi até engraçado, ela disse assim "Esse verde tá de vez" quer dizer, está amarelando, está maduro. Eu achei que isso foi interessante (técnica

Tanto a equipe da Ação Educativa como as profissionais do Demec estiveram envolvidas com um conjunto de estratégias de sustentação para efetivar a implementação das ações previstas pelas escolas. Do lado da Ação Educativa, como mencionado, foram organizados encontros periódicos, seja junto às escolas, com a participação de representantes das equipes técnicas e do Conselho de Escola, seja junto ao Demec, com a participação da equipe pedagógica, a própria dirigente e as supervisoras.

Do lado do Demec, além das ações de mobilização, as profissionais criaram uma sistemática de acompanhamento direto às escolas, por meio da elaboração de um instrumento de observação baseado tanto nos indicadores propostos pelo Indique, como nas ações previstas e desenvolvidas pelas escolas para darem conta de seus planos. O Demec organizou-se, ainda, na perspectiva de realizar visitas em todas as escolas, procurando conhecer os resultados que vinham sendo alcançados, as dificuldades de execução, bem como orientar possíveis soluções para essas dificuldades. Nesse sentido, é possível afirmar que as estratégias planejadas pelo Departamento passaram a integrar os próprios planos de ação, na medida em que os realimentaram e lhes forneceram novos caminhos. Caso o Demec não tivesse uma participação ativa no acompanhamento e na sustentação dos planos e estes ficassem somente sob a responsabilidade das escolas, mesmo assim, o plano poderia ganhar mobilidade, já que as escolas, para darem conta de suas próprias demandas, teriam de investir na criação de condições para tanto. Porém, a participação efetiva do Demec parece ter criado uma mobilidade ainda maior, enriquecendo as possibilidades de implementação, constituindo-se como parceira das escolas, cuidando para que os planos não tivessem uma vida efêmera perante as dificuldades percebidas.

4 A avaliação de cada indicador e das perguntas que permitem avaliá-lo é feita por meio de cores: verde se a prática e/ou ação já está consolidada na escola; amarelo se a ação e/ou prática não pode ser considerada recorrente ou consolidada e, portanto, merece atenção; e vermelho se a ação e/ou prática é inexistente e a intervenção precisa ser imediata. 
A ideia de um projeto pedagógico, visando a melhoria desse mundo com relação a suas práticas específicas, será uma ficção burocrática se não for fruto da consciência e do esforço da coletividade escolar. Por isso, é ela, a escola que precisa ser assistida e orientada sistematicamente (AZANHA, 1998).

É por meio de um percurso como esse, em que o Indique foi explorado em muitas de suas potencialidades, em que foi concebido um processo de acompanhamento à implementação dos planos de ação das escolas e em que a comunidade escolar pôde conferir e refletir sobre os resultados alcançados, que as redes de educação podem construir os sentidos da autoavaliação (RIBEIRO; GUSMÃO, 2010).

\section{AS ESCOLAS do MUNICíPIO dE BEBEdouRo E SUAS AGENDAS}

0 processo avaliativo realizado pela rede municipal de ensino de Bebedouro revelou um conjunto de agendas que as escolas elegeram como prioritárias em busca da qualidade da educação. Essas agendas foram se configurando a partir das dimensões propostas pelo Indique para a autoavaliação das escolas. De modo geral, todas as dimensões foram consideradas pela maioria das escolas, e todos os indicadores propostos para cada dimensão foram avaliados, embora a prioridade dada a eles tenha variado.

Tabela 2 - Dimensões escolhidas nos planos de ação por quantidade de escolas

\begin{tabular}{|c|c|c|}
\hline Dimensão & $\begin{array}{l}\text { Número de } \\
\text { escolas }\end{array}$ & $\begin{array}{l}\text { \% em relação } \\
\text { à rede de } \\
\text { ensino }\end{array}$ \\
\hline Gestão escolar democrática & 12 & $100 \%$ \\
\hline Ambiente educativo & 09 & $75 \%$ \\
\hline Prática pedagógica e avaliação & 09 & $75 \%$ \\
\hline $\begin{array}{l}\text { Ensino e aprendizagem da leitura e da } \\
\text { escrita }\end{array}$ & 09 & $75 \%$ \\
\hline Ambiente físico escolar & 09 & $75 \%$ \\
\hline $\begin{array}{l}\text { Formação e condições de trabalho dos } \\
\text { profissionais da escola }\end{array}$ & 08 & $67 \%$ \\
\hline $\begin{array}{l}\text { Acesso e permanência dos alunos na } \\
\text { escola }\end{array}$ & 06 & $50 \%$ \\
\hline
\end{tabular}

Fonte: Relatório analítico dos resultados da utilização dos Indicadores da Qualidade na Educação pelas escolas da rede municipal de Bebedouro/SP. Ação Educativa, 2011. 
A análise dos planos de ação elaborados pelas escolas sugere fortemente que elas buscam criar no ambiente educativo uma cultura de convivência sustentada por uma ética que privilegia basicamente a solidariedade, 0 respeito às diferenças e a resolução pacífica de conflitos. Os planos de ação manifestaram uma preocupação marcante quanto à relação que alunos e familiares, bem como professores e demais funcionários, estabelecem com o ambiente escolar. 0 processo avaliativo indica que é desejo da escola que todos estabeleçam com ela uma relação afetiva e prazerosa. As estratégias e ações propostas vão justamente ao encontro desse desejo, inclusive quando consideram que criar essa cultura de convivência também representa para as escolas a problematização do Estatuto da Criança e do Adolescente, pois apostam que por meio da ampla discussão desse documento junto à comunidade será possível conscientizar a todos da importância de uma convivência pacífica, sem discriminações de qualquer natureza. No entanto, não podemos deixar de ponderar que na ordem cultural em que vivemos essa meta não é de fácil alcance, pois requer que a própria comunidade escolar estabeleça, exerça, sustente, revise constantemente e divulgue regras de convivência e de cidadania.

Não é de hoje que as escolas, de modo geral, vêm procurando modificar o clima de agressividade e conflitos que as atravessam em diferentes graus, bem como a falta de respeito entre os profissionais e os alunos e entre os próprios alunos. Para tanto, a escola tem procurado soluções que buscam valorizar a participação de alunos e familiares como corresponsáveis pela gestão da vida escolar. Admite, ainda, que essa corresponsabilidade se estende, inclusive, à aprendizagem dos conteúdos escolares, pois procura criar condições para que familiares e alunos avaliem seu desempenho e se responsabilizem por ele. Ou seja, as avaliações são unânimes em afirmar que a escola sozinha não tem conseguido modificar essa situação e, cada vez mais, tem procurado parcerias não somente junto à comunidade, mas também junto a organizações da sociedade civil. Parece-nos que esta tem sido uma das demandas mais fundamentais das escolas no sentido de que ela tem sustentado a esperança de professores e equipes técnicas em mudar o ambiente escolar e, em torno da qual, outras agendas estão articuladas. É o caso, por exemplo, da qualidade do espaço escolar, particularmente no que se refere à necessidade de se preservar o que já se tem, reconhecendo que a escola é um equipamento social público. Mais do que preservar, no entanto, as avaliações apontam para a necessidade de todos se comprometerem com uma visão de escola que compreende o espaço escolar como construção cultural, que expressa e reflete, para além de sua materialidade, a perspectiva 
de uma sociedade justa e democrática. Assim, as avaliações não ignoram que é também no âmbito do espaço escolar, de sua arquitetura, que as relações pedagógicas se desenvolvem. Consideram, então, que esse espaço pode e deve ser um aliado na educação e, como tal, mostrou-se presente nos planos de ação, na perspectiva de contribuir para a aprendizagem, inclusive de alunos com necessidades especiais, de favorecer as interações da comunidade escolar e de investir na melhoria da qualidade de vida das pessoas que ali convivem.

Não há dúvida de que desenvolver um processo educativo apoiado numa gestão democrática é um dos maiores desafios que se coloca para as escolas. Mas em suas avaliações as escolas mostram-se dispostas a enfrentar esse desafio, seja por meio da perspectiva de implementar uma cogestão da vida escolar com pais, alunos, funcionários, professores, diretores e coordenadores pedagógicos, seja pela constituição de conselhos escolares atuantes. Para a comunidade escolar, os Conselhos Escolares constituem-se em campos legítimos de gestão compartilhada não apenas do cotidiano institucional, mas também da própria proposta curricular da escola. Consideram, ainda, que esses fóruns de deliberação têm um papel preponderante na coordenação e no acompanhamento do projeto político-pedagógico da escola. Ou seja, esses conselhos são reconhecidos pelas escolas como instâncias deliberativas legítimas que possuem, entre outras atribuições, a definição de eventos dentro do calendário escolar, a discussão de métodos mais atraentes para o ensino do conteúdo de determinadas disciplinas, a definição de critérios para transferência de alunos e até mesmo a administração dos recursos financeiros.

As avaliações revelam, ainda, a busca da criação de práticas efetivas de gestão de seus projetos político-pedagógicos, na medida em que grande parte das ações propostas refere-se basicamente à sua divulgação e à sua elaboração com a participação da comunidade escolar. De modo geral, as soluções propostas consideram que a comunidade escolar, para enfrentar esses problemas, deve avaliar de forma sistemática a função social da escola no que se refere às finalidades da educação que pratica. Em outras palavras, a ideia é que o PPP tem o seu valor não tanto como produto, mas principalmente como processo para constituição do coletivo escolar. Pode-se dizer que, nessa perspectiva, as escolas têm como pressuposto a crença de que esse processo pode criar um espaço de produção de conhecimentos no qual a elaboração do PPP orienta-se pela possibilidade de troca e de cooperação, o que implicaria em repercussões sobre o desejo de futuro dos envolvidos. 
É no âmbito da elaboração dos PPPs que as escolas manifestam a necessidade de investir no desenho de práticas pedagógicas inclusivas, que atendam a alunos com deficiência, bem como conceber formas variadas e transparentes de avaliação e monitoramento da aprendizagem de todos os alunos. Essas agendas estão, ainda, relacionadas à necessidade de as escolas se constituírem num ambiente de letramento. Para tanto, as escolas buscam, por um lado, dedicar-se intensamente ao processo de alfabetização das crianças e dos alunos com dificuldades em leitura e escrita e, por outro, ampliar essas capacidades ao longo do ensino fundamental. Mais uma vez as escolas consideram a relevância de constituir um ambiente educativo adequado, que nesse caso se revela em cada vez mais facilitar o acesso às bibliotecas, às salas de leitura e de informática e, ao mesmo tempo, implementar estratégias que criem condições para que esses espaços sejam bem aproveitados. Há nesse sentido um reconhecimento das escolas de que a aprendizagem inicial da língua escrita, bem como o processo de letramento, exigem múltiplas metodologias e requerem, também, o desenvolvimento de programas de formação dos professores do ensino fundamental. No entanto, a demanda de formação de professores não se limita às questões de alfabetização e letramento, mas, sobretudo, às questões relacionadas com a capacitação continuada de professores para o ensino de alunos com necessidades especiais. Há que se destacar também que as escolas ressentem-se da falta de formação para os coordenadores pedagógicos, demanda esta que se mostrou bastante enfatizada no desenho dos planos.

Todas as agendas aqui explicitadas têm como suas principais metas 0 acesso, a permanência e a aprendizagem dos alunos no ambiente escolar. A frequência irregular dos alunos, que pode ser caracterizada como exclusão na escola, coloca-se para as unidades educacionais como elemento para avaliar quer o projeto político-pedagógico, quer as relações com os estudantes e suas famílias, ou ainda, as estratégias planejadas para a ação educativa em curso. Nessa perspectiva, as escolas concebem ações que buscam o acesso, a permanência, a socialização e a aquisição do conhecimento, tendo em vista garantir a plenitude do direito à educação. Nessa empreitada, os planos das escolas contam com a ajuda de aliados como os Conselhos Tutelares e outros elementos da rede de proteção, além do envolvimento mais efetivo de estudantes, familiares e comunidade em geral no monitoramento da frequência e desempenho escolar.

A aposta das escolas em seus planos para promover a permanência e o sucesso dos estudantes passa pela garantia de algumas condições 
necessárias como a efetivação dos espaços de participação da escola, a diminuição da quantidade de alunos por sala de aula e o funcionamento de uma rede de proteção, além da implicação de estudantes e familiares com a aprendizagem, por meio de levantamento de suas expectativas com relação à escola, autoavaliação dos alunos e maior investimento nas reuniões junto aos familiares. Dessa forma, vale lembrar que investir esforços no planejamento de experiências didáticas inovadoras que tenham potencial para capturar o estudante faz parte da função social da escola. Mas não podemos ignorar que a proposição dessas experiências deve levar em conta a complexidade intrínseca aos processos de ensino e de aprendizagem, complexidade essa que transcende o campo da cognição.

AS AGENDAS DAS ESCOLAS E A GESTÃO DO DEMEC: ALGUMAS CONSIDERAÇÕES FINAIS

Para dar conta de suas agendas, todas as escolas desenharam estratégias de ação que começaram a ser efetivamente implementadas no início de 2011. Dentre essas estratégias, há uma que foi bastante privilegiada, independentemente da dimensão considerada: comprometimento dos familiares com a gestão da escola. Conforme relato das escolas, essa foi uma meta alcançada em grande parte com a utilização do Indique. 0 que se observa é que em cinco das sete dimensões as escolas afirmam que houve uma mudança significativa na participação dos familiares em diferentes instâncias e contextos do cotidiano escolar. Consideram, assim, que houve maior participação dos familiares na elaboração ou na discussão do projeto político-pedagógico, na resolução de conflitos envolvendo estudantes, nos avanços obtidos em leitura e escrita, na divulgação de eventos da escola, na discussão de diversos temas educacionais (ética, ECA, inclusão), nos Conselhos e nas decisões escolares, nas articulações entre os professores do ensino regular e aqueles que atendem as crianças com deficiência. De modo geral, os planos de ação já demonstravam enfaticamente essa demanda na perspectiva de enfrentar dificuldades de diferentes naturezas.

No entanto, caberia destacar que a necessidade de trazer os familiares para dentro da escola parece também se justificar pelo fato de a escola ter assumido para si um conjunto de tarefas e de responsabilidades do qual ela não tem conseguido dar conta sozinha. Parece-nos, ainda, que muitas dessas responsabilidades não são propriamente do âmbito da educação escolar. A nosso ver, a ênfase dada a essa agenda parece apontar, como argumenta Nóvoa (2009), para um transbordamento da função social da escola nos tempos atuais, no sentido de atender às necessidades de uma escola utópica 
que procura compensar as "deficiências da sociedade" chamando a si todas as missões possíveis e imagináveis.

O trabalho escolar tem duas grandes finalidades: por um lado, a transmissão e apropriação dos conhecimentos e da cultura; por outro lado, a compreensão da arte do encontro, da comunicação e da vida em conjunto. É isto que a escola sabe fazer, é isto que a escola faz melhor. É nisto que ela deve concentrar suas prioridades, sabendo que nada nos torna mais livres do que dominar a ciência e a cultura, sabendo que não há diálogo, nem compreensão do outro sem o treino da leitura, da escrita, da comunicação, sabendo que a cidadania se conquista desde logo na aquisição dos instrumentos de conhecimento e de cultura que nos permitam exercê-la. [...]

[...] Uma coisa é dizer que a escola deve recentrar-se na aprendizagem, não ignorando que ela só é possivel se atendermos a um conjunto de circunstâncias da vida pessoal e social das crianças. E outra, bem diferente, é dizer que a escola deve assumir como responsabilidade sua essa vastidão de tarefas que lhe fomos atribuindo (NÓVOA, 2009, p. 63).

Ao trazer essas considerações de Nóvoa, nossa intenção foi problematizar particularmente essa agenda, pois acreditamos que seria importante as escolas a avaliarem mais sistematicamente. A aproximação dos familiares da escola é uma agenda que parece pretender diferentes objetivos, que vão desde a possibilidade de conscientizar a comunidade sobre as responsabilidades que são dela e não da escola, até a participação efetiva na gestão da escola. Há que se considerar, no entanto, que falta clareza para as escolas dos limites de uma cogestão, particularmente sobre os aspectos em que essa cogestão pode ocorrer. Até por falta dessa clareza parece que se espera um voluntarismo dos familiares na participação dentro da escola. Ressalta-se, ainda, que a participação da comunidade no processo de gestão das escolas públicas requer mais que aparato legal, ou institucional; requer, na verdade, um conjunto de iniciativas que possibilitem que tal ação seja efetiva e que contribua superando os limites de tempo, espaço, formação escolar, relações de poder, representatividade e o acesso às informações.

No que se refere particularmente à participação da comunidade nas decisões e encaminhamentos de natureza pedagógica, pudemos notar que uma das diretoras percebeu que essa é uma demanda que precisa ser cuidada e refletida. Como considera essa diretora, a comunidade consegue fazer aquilo sobre o que ela tem conhecimento. Nesse sentido, as escolas precisam ter mais claro o que esperam quando requerem a participação da comunidade na gestão escolar, já que o monitoramento das práticas pedagógicas e da aprendizagem dos alunos, em princípio, está sob a responsabilidade da própria escola. Isso não quer dizer que não possa existir um nível de questionamentos sobre essas decisões por parte da comunidade. Mas mesmo nesse caso, a escola 
precisa criar condições para que esses questionamentos possam se efetivar e contribuir para o projeto pedagógico.

O olhar do coletivo mudou muito, inclusive o nosso para orientar a comunidade, porque a comunidade consegue fazer aquilo que tem prática, por exemplo, se eu preciso de uma pessoa para ajudar a tirar o mato, o senhorzinho, vô do aluno: "Pode deixar, eu faço isso pra senhora". Se eu preciso fazer bolo numa festinha, as mães: "Pode deixar, a gente faz". Agora, opinar na parte financeira, na parte de avaliação, na parte de aprendizagem era mais difícil. Quando a gente se reunia, eles falavam: "Ah, do jeito que a senhora fizer está bom!” Hoje não, essa visão já mudou. Depois que a gente fez o plano de ação, apresentou, todo mundo concordou, todo mundo participou do Indique, então mudou um pouquinho. Hoje a gente já consegue, embora ainda timidamente. Já estão apoiando as ações, assim se manifestando. Ao longo deste ano a gente foi fazendo reuniões, formações e informando também, estamos conversando com a comunidade (diretora Emef Isabel Motta, 19 abr. 2012).

Embora todas as escolas pareçam dar mais prioridade a diversos aspectos que transcenderiam uma função social centrada na aprendizagem, não deixaram de destacar em seus planos de ação a necessidade de formação continuada de seus profissionais. Essa agenda se evidenciou não apenas nos planos, mas também num encontro de todas as escolas com o Demec em que foi pautada pela equipe da Ação Educativa a discussão de prioridades que, na perspectiva das escolas, deveriam orientar as ações futuras do Departamento. Nesse encontro as escolas do Ciclo II manifestaram-se quanto à importância de o Departamento investir em programas de formação dos professores nas diversas áreas do conhecimento, porém fora do horário de trabalho. Ainda dentro dessa dimensão, o Ciclo I demandou diversas ações de formação dos profissionais e de acompanhamento das práticas de coordenação pedagógica. Consideraram a necessidade de encontros sistemáticos do Departamento com os coordenadores pedagógicos para subsidiar esses profissionais na condução dos HTPCs, no acompanhamento de sala de aula, nas reuniões dos conselhos de classe.

Efetivamente, o Demec pôde dar conta de muitas dessas demandas e, para tanto, se orientou por uma prática pautada pela participação ativa no cotidiano das escolas, por meio de visitas de acompanhamento planejadas, com a elaboração prévia de roteiros baseados nos planos de ação das escolas e nos materiais do Indique. 
[...] a gente foi pra escola pra ver o que podíamos fazer. Então hoje nós temos a noção do que cada escola precisa e o que a rede como um todo pede também (técnica do Demec, 19

abr. 2012).

A gente conseguiu [elaborar o plano do Demec] porque hoje a gente tem em mãos as reinvindicações [...] de todos da escola. Então é um documento que ganhou força inclusive para levarmos para o executivo, para o prefeito, para pedir algumas questões apontadas

não só pelo Departamento, mas com uma força maior porque vem de dentro da escola (técnica do Demec, 19 abr. 2012).

A gente não está definindo por eles o que eles precisam, estamos ouvindo o que eles precisam [...] a gente consegue ouvir mais e ser ouvido também. Então acho que houve uma relação de estreitamento com as escolas (técnica do Demec, 19 abr. 2012).

Essa opção do Departamento, além de ter se mostrado promissora, ganhou o reconhecimento das escolas.

O Demec foi além do que a gente esperava, só que algumas coisas a gente ainda não conseguiu, a gente vai demandar outros encontros, outras discussões pra conseguirmos encaminhar outras demandas [...] mas acho que a expectativa foi além do que a gente esperava [...] eu não esperava no começo do projeto que o Demec fosse conseguir acompanhar tão de perto e conseguiu. [...] Aquele encontro de formação em que as escolas explicitaram suas demandas para o Demec foi muito válido e várias daquelas ações foram viabilizadas. Então eu acho que foi muito produtivo (diretora Emef Isabel Motta, 19 abr. 2012).

A maneira pela qual o Demec decidiu encaminhar e apoiar os planos de ação das escolas vem ao encontro do que Nóvoa aponta como uma estratégia privilegiada para enfrentar as dificuldades que a instituição escolar tem encontrado para recriar sua função social. Em sua visão, é urgente que as escolas se constituam em comunidades de prática, isto é, em "grupos de educadores comprometidos com a pesquisa e a inovação, nos quais se discutem ideias sobre o ensino e aprendizagem e se elaboram perspectivas comuns sobre os desafios da formação pessoal, profissional e cívica dos alunos" (NÓVOA, 2010, p. 21).

Caberia destacar, finalmente, que para a elaboração e execução do plano de gestão educacional do munícipio, o Departamento se pautou por uma conduta que priorizou um processo participativo e democrático junto à rede de ensino. Desde a etapa de mobilização da comunidade com apoio no Indique até a concretização de um plano construído junto ao coletivo das escolas, o Demec planejou e implementou diversas ações que resultaram num documento que reflete as agendas de todas as escolas e que, portanto, possui a legitimidade almejada pela Dirigente de Ensino na medida em que atende aos anseios da comunidade escolar e, ao mesmo tempo, dá força para exigir das instâncias 
centrais as condições requeridas para uma educação de qualidade. Esse processo participativo, como procuramos darvisibilidade, foi sendo construído por meio da organização da comunidade em torno de um projeto político e não em torno de um voluntarismo que aposta na participação pela participação. 


\section{Quality indicators in education: schools agendas directing municipalities' educational policies}

Abstract: This article analyses an institutional self-evaluation methodology for schools: Indicadores da Qualidade na Educação and its contributions in participative processes to construct educational projects, the use of which has been recommended by Ação Educativa in a partnership with Undime and MEC. Indicadores' main purpose is the participation of the school community in the battle for improving education quality. Analysis will be made considering challenges in the education field: participation in educational processes; school assessment and legitimacy before those in charge for decision-making. Based on one experiment we can conclude that the above mentioned material is potentially effective in its capacity to increase dialogue between schools and educational systems' departments and that it legitimizes and supports claims towards central instances for necessary conditions for a better quality education.

Keywords: School self-evaluation. Educational participation. Educational assessment processes. Quality in education. Educational projects. 


\section{REFERÊNCIAS}

AÇÃO EDUCATIVA et al. Indicadores da qualidade na educação. São Paulo: Ação Educativa, 2007.

AGUERRONDO, Inês. La calidad de la educación: ejes para su definición e evaluación. La educación. Revista Interamericana de Deserrollo Educativo, v. 116, n. 37, p. 561-578, 1993.

AZANHA, José Mário Pires. Proposta pedagógica e autonomia da escola. Cadernos de História e Filosofia da Educação, v. 2, n. 4, p. 11- 21, 1998.

BRITO, Kátia C.; BORGES, Nádia F. V. Gestão democrática: da aprendizagem ao discurso. Disponível em: 〈http://www.simposioestadopoliticas.ufu.br/ imagens/anais/pdf/DC24.pdf〉. Acesso em: 28 jun. 2012.

CABRAL, Karina Melissa; GIORGI, C. A. G. A Busca por uma escola melhor: uma análise da democratização da escola segundo Paulo Freire. In: XI CONGRESSO ESTADUAL PAULISTA SOBRE FORMAÇÃO DE EDUCADORES E I CONGRESSO NACIONAL DE FORMAÇÃO DE PROFESSORES. Anais... Águas de Lindóia: PróReitoria de Graduação da Universidade Estadual Paulista Júlio de Mesquita Filho (Unesp), 2011. v. 1, p. 1-15.

CORRÊA, Bianca Cristina. Considerações sobre qualidade na educação infantil. Cadernos de Pesquisa, São Paulo, s/v, n. 119, p. 85-112, jul. 2003.

FERNANDES, Domingos. Avaliação de programas e projetos. Lisboa [s/d]. Mimeo. [Texto de aula oferecida na condição de convidado, Feusp, maio 2009].

FREIRE, Paulo. À sombra desta mangueira. São Paulo: Olho d’Água, 1995.

GAMBOA, Silvio A. S. Análise epistemológica dos métodos na pesquisa educacional: um estudo sobre as dissertações de mestrado em educação da UnB. Brasília: Faculdade de Educação UnB, 1982.

NÓVOA, António. Professores do futuro presente. Lisboa: Instituto de Educação da Universidade de Lisboa; Educa, 2009.

RIBEIRO, V. M.; RIBEIRO, V. M; GUSMÃO, J. B. Indicadores da qualidade para a mobilização da escola. Cadernos de Pesquisa, São Paulo, v. 35, n. 124, p. 227-251, jan./abr. 2005.

; GUSMÃO, Joana B. Uma leitura dos usos dos Indicadores de 
Qualidade na Educação. Cadernos de Pesquisa, São Paulo, v. 40, n. 141, p. 823-847, set./dez. 2010.

SOUSA, Sandra Maria Zákia. Avaliação escolar: constatações e perspectivas. Revista de Educação AEC, Brasília, ano 24, n. 94, p. 59-66, jan./mar. 1995. In: LUCE, Maria Beatriz; MEDEIROS, Isabel Letícia P. (Orgs.). Gestão escolar democrática: concepções e vivências. 1. ed. Porto Alegre: UFRGS Editora, 2006.

RECEBIDO: Março de 2014.

APROVADO: Abril de 2014. 